ARTICLE

Received 2 May 2014 | Accepted 10 Jun 2014 | Published 9 Jul $2014 \quad$ DOl: 10.1038/ncomms5365

\title{
Spirocyclic hypervalent iodine(III)-mediated radiofluorination of non-activated and hindered aromatics
}

\author{
Benjamin H. Rotstein ${ }^{1, \star}$, Nickeisha A. Stephenson ${ }^{1, \star}{ }^{\text {, Neil Vasdev }}{ }^{1}$ \& Steven H. Liang ${ }^{1}$
}

Fluorine-18 $\left(t_{1 / 2}=109.7 \mathrm{~min}\right)$ is the most commonly used isotope to prepare radiopharmaceuticals for molecular imaging by positron emission tomography (PET). Nucleophilic aromatic substitution reactions of suitably activated (electron-deficient) aromatic substrates with no-carrier-added $\left[{ }^{18} \mathrm{~F}\right]$ fluoride ion are routinely carried out in the synthesis of radiotracers in high specific activities. Despite extensive efforts to develop a general ${ }^{18} \mathrm{~F}$-labelling technique for non-activated arenes there is an urgent and unmet need to achieve this goal. Here we describe an effective solution that relies on the chemistry of spirocyclic hypervalent iodine(III) complexes, which serve as precursors for rapid, one-step regioselective radiofluorination with $\left[{ }^{18} \mathrm{~F}\right]$ fluoride. This methodology proves to be efficient for radiolabelling a diverse range of non-activated functionalized arenes and heteroarenes, including arene substrates bearing electron-donating groups, bulky ortho functionalities, benzylic substituents and meta-substituted electron-withdrawing groups. Polyfunctional molecules and a range of previously elusive ${ }^{18} \mathrm{~F}$-labelled building blocks, compounds and radiopharmaceuticals are synthesized.

\footnotetext{
${ }^{1}$ Division of Nuclear Medicine and Molecular Imaging, Center for Advanced Medical Imaging Sciences, Massachusetts General Hospital \& Department of Radiology, Harvard Medical School, 55 Fruit Street, Boston, MA 02114, USA. * These authors contributed equally to this work. Correspondence and requests for materials should be addressed to N.V. (email: vasdev.neil@mgh.harvard.edu) or to S.H.L. (email: liang.steven@mgh.harvard.edu).
} 
luorine-18 $\left({ }^{18} \mathrm{~F} ; t_{1 / 2}=109.7 \mathrm{~min}\right)$ labelled compounds and - radiopharmaceuticals are the mainstay of functional molecular imaging by positron emission tomography (PET) for a broad range of applications including clinical diagnosis and drug discovery ${ }^{1-5}$. Consequently, there is a rapidly growing demand for new ${ }^{18} \mathrm{~F}$-labelled agents to probe biological processes and targets in vivo ${ }^{6}$. Fluorine-18 is most readily prepared in high specific activity as no-carrier-added $\left[{ }^{18} \mathrm{~F}\right]$ fluoride ion, by proton irradiation of $\left[{ }^{18} \mathrm{O}\right] \mathrm{H}_{2} \mathrm{O} \quad\left({ }^{18} \mathrm{O}(\mathrm{p}, \mathrm{n}){ }^{18} \mathrm{~F}\right.$ nuclear reaction) in medical cyclotrons. Most ${ }^{18} \mathrm{~F}$-labelling methodologies for nucleophilic aromatic substitution $\left(\mathrm{S}_{\mathrm{N}} \mathrm{Ar}\right)$ reactions employ 'naked' $\left[{ }^{18} \mathrm{~F}\right]$ fluoride ion with appropriately activated (electrondeficient) aromatic/heteroaromatic substrates. However, radiofluorination of non-activated arenes represents a major challenge in the field and there is an urgent need for a general and practical methodology that can introduce ${ }^{18} \mathrm{~F}$ into molecules that cannot be labelled using a conventional $\mathrm{S}_{\mathrm{N}} \mathrm{Ar}$ reaction.

Reactions of non-activated arenes with $\left[{ }^{18} \mathrm{~F}\right]$ fluoride by Balz-Schiemann reactions with diazonium tetrafluoroborate salts $^{7}$ or Wallach reactions with triazene-based precursors ${ }^{8}$ have proven to be inefficient and low yielding. Other efforts to achieve this goal include applications of triarylsulphonium salts ${ }^{9}$, diarylsulphoxides ${ }^{10}$ or the post- $S_{N} A r$ conversion of activating, electron-withdrawing groups into electron-donating groups, for example, through Baeyer-Villiger oxidation ${ }^{11}$, all of which are based on reactions towards electron-deficient arenes and have limited substrate scope. Alternatively, transition-metal-mediated fluorination reactions (Fig. $1 \mathrm{a}, \mathbf{1})^{12,13}$ and oxidative fluorination of phenol derivatives ${ }^{14}$ (Fig. 1a, 2) have been investigated. Unfortunately, the latter two methods employ air-sensitive complexes of toxic metals (1) or have yet to demonstrate extensive substrate scope (2).

The introduction of $\left[{ }^{18} \mathrm{~F}\right]$ fluoride ion into electron-rich or -deficient arenes via diaryliodonium salt-based precursors (Fig. 1a, 3) $)^{15-17}$ has been recently reviewed ${ }^{18,19}$. This technology has been successfully used to prepare PET radiopharmaceuticals. However, ${ }^{18} \mathrm{~F}$-incorporation into the relatively electron-deficient (activated) arene is accompanied by production of undesired radioactive byproducts arising from the electron-rich aryl auxiliary. ${ }^{17,20}$ Although diaryliodonium salts represent the most investigated class of hypervalent iodine(III) compounds in PET, there is scant patent literature ${ }^{21}$ on how one might achieve the desired regiospecific radiofluorination based on the use of aryliodonium ylides (ArI $=\mathrm{CX}_{2} ; \quad \mathrm{X}=$ electron-deficient substituent) as precursors with Meldrum's acid auxiliaries.

Here we report a spirocyclic hypervalent iodine(III)-mediated radiofluorination strategy, based on iodonium ylides (Fig. 1b, 4), to afford ${ }^{18} \mathrm{~F}$-aryl fluorides in high radiochemical yields. The technique involves stable, easily purified precursors and is readily implemented with standard workup procedures. The conceptual advantages of excellent regioselectivity and viability of incorporation of ${ }^{18} \mathrm{~F}$ into a wide array of non-activated (hetero)arenes make this methodology suitable for routine radiopharmaceutical production.

\section{Results}

Design of spirocyclic iodonium ylides for radiolabelling. The initial goal of the present work was to discover an optimally

a Previous work on precursor design

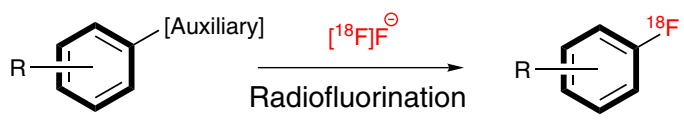

Auxiliary serves as a leaving group

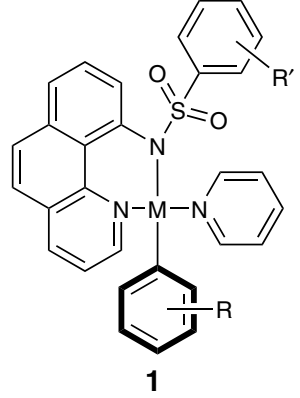

Metal complexes $\mathrm{M}=\mathrm{Pd}$ or $\mathrm{Ni}$

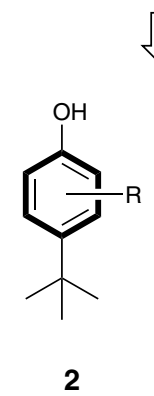

Phenolic substrates

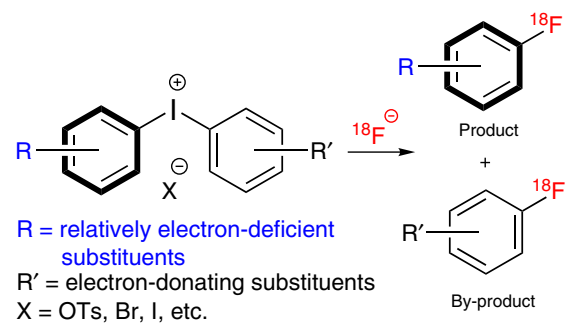

3

Diaryliodonium salts

b This work

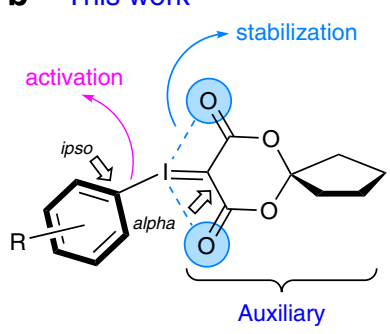

4

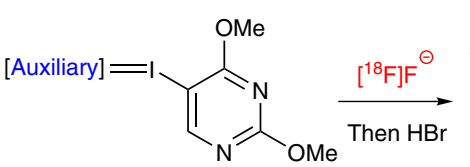

stable precursor<smiles>O=c1[nH]cc(F)c(=O)[nH]1</smiles>

$5-\left[{ }^{18} \mathrm{~F}\right] \mathrm{fluorouracil}$
Isolated yield

$11 \pm 4 \%(n=3)$

Specific activity

Spiroiodine(III)

- Regioselective

- Metal-free

- Broad substrate scope

- Suitable for PET radiopharmaceutical production

Figure 1 | Direct radiofluorination of non-activated arenes. (a) Previous work on precursor design. (b) This work. 
a Proposed pathway

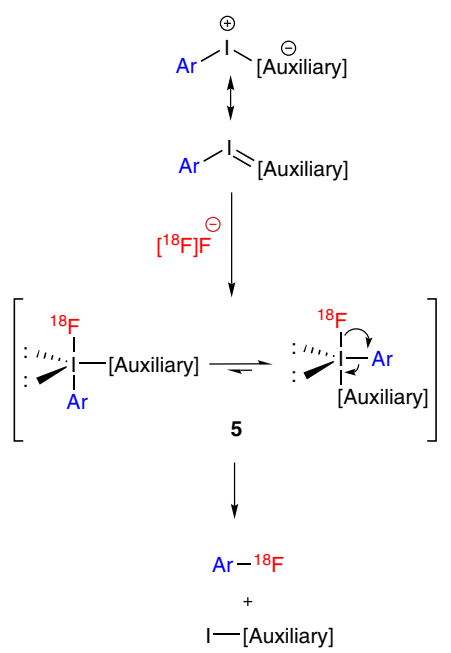

b Development of spiroiodine(III) ligands

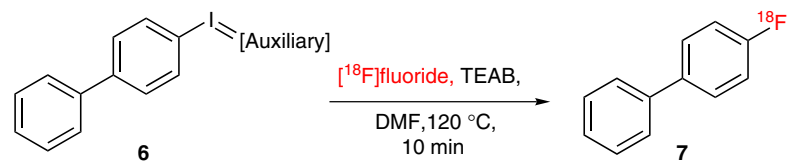

[Auxiliary]<smiles>CCN1C(=O)C(=O)N(P)C(=O)C1=O</smiles>

$\mathbf{8 a} \mathrm{R}=\mathrm{Me}$
$\mathbf{8 b} \mathrm{R}=\mathrm{H}$
$\mathbf{8 c} \mathrm{R}=\mathrm{Cy}$
$\mathbf{8 d} \mathrm{R}=\mathrm{Ph}$
Unstable at r.t.t<smiles>O=C1OC2(CCCCC2)OC(=O)C1=O</smiles>

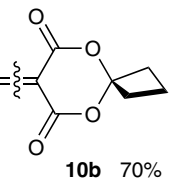

$\mathrm{R}_{1}=\mathrm{Me} \quad 47 \% \Rightarrow$ $\mathrm{R}_{2}=\mathrm{Me}$

$9 \mathrm{~b} \mathrm{R}_{1}=\mathrm{Et}$,

$\mathrm{R}_{2}=\mathrm{Et}$

9c $\mathrm{R}_{1}=\mathrm{Me}$

$R_{2}=B \mathrm{Bu}$

9d $R_{1}=M e$

$\mathrm{R}_{2}=n \mathrm{Hexyl}$

Oily compounds

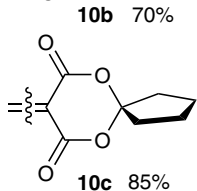

Figure 2 | Development of spirocyclic iodonium ylides for radiofluorination. (a) Proposed pathway. Radiofluorination of spiroiodonium ylides is proposed to occur through trigonal bipyramidal intermediate 5. (b) Development and screening of spiroiodine(III) ligands. Conditions: biphenyl spiroiodine(III) precursor $(2 \mathrm{mg}), \operatorname{TEAB}(7 \mathrm{mg}), \mathrm{DMF}(400 \mu \mathrm{l}), 120^{\circ} \mathrm{C}, 10 \mathrm{~min}$. Incorporation yield and product identity were determined by radioTLC and radioHPLC, respectively $(n=3)$. TEAB, tetraethylammonium bicarbonate; DMF, $N, N$-dimethylformamide.

designed auxiliary (Fig. 1b, 4) capable of stabilizing the I(III) centre of the iodonium ylide precursors, particularly if bound to non-activated arenes, thereby disfavouring notorious I(III) decomposition $^{22}$ and disproportionation ${ }^{23}$ pathways. As shown in Fig. 2a, the extent of such stabilization should still enable the formation of ${ }^{18} \mathrm{~F}$-labelled products via the addition/reductive elimination mechanism ${ }^{16,24}$ that has been invoked for diaryliodonium salts and other I(III) species ${ }^{15-17,20,25,26}$. Initial experiments (Fig. 2b) with derivatives of Meldrum's acid 9a and barbituric acid $\mathbf{8 a}$, based on a challenging electron-neutral biphenyl substrate, provided radiochemical conversions of $47 \%$ and $53 \%$, respectively. Analogues incorporating substituents on the nitrogen atoms of barbiturates $\mathbf{8 b}-\mathbf{d}$ or alkyl groups other than methyl on the quaternary carbon of diesters $\mathbf{9 b}-\mathbf{d}$ either exhibited poor stability at room temperature or were thick oils that were difficult to handle. These fruitless attempts led us to study a unique spirocyclic scaffold, which is rarely utilized in organic chemistry and has not been previously explored in radiochemistry. Gratifyingly, a spirocyclohexyl precursor, 10a, was a stable crystalline solid that showed reactivity towards ${ }^{18}$ F-fluoride ion similar to that of 9 a (52\% incorporation yield). The well-tolerated initial reactions with 10a inspired us to modulate smaller spirocycles and we discovered that cyclobutyl $\mathbf{1 0 b}$ and cyclopentyl 10c groups led to significantly increased conversions, $70 \%$ and $85 \%$, respectively (Fig. 2b; Supplementary Fig. 1). The biphenyl precursor 10c exhibited a significantly enhanced thermal stability over congeners incorporating alternative ligands under analogous radiolabelling conditions (DMF, $120^{\circ} \mathrm{C}, 10 \mathrm{~min}$ ).

The labelling precursors 13 (Fig. 3a) were easily synthesized from the corresponding aryl iodine(III) derivatives $\mathbf{1 2}$ or by a one-pot procedure from aryl iodide 11. These reactions were typically carried out under 'open-flask' conditions (Supplementary Methods) and in all cases afforded crystalline products. Among many commonly-used radiolabelling conditions, a simple combination of dried $\left[{ }^{18} \mathrm{~F}\right]$ fluoride with tetraethylammonium bicarbonate $\left(\mathrm{TEAB}^{27}\right)$ and spirocyclic iodine precursor in DMF was deemed to be optimal (Supplementary Table 1). The use of 2,2,6,6-tetramethyl-1piperidinyloxy and butylated hydroxytoluene, as radical scavengers, offered no improvement of radiolabelling efficiency. As shown in Fig. 3b, hindered alkyl substituents without activating groups were successfully radiolabelled with ${ }^{18} \mathrm{~F}$ in 45-56\% incorporation yield (15 and 16, Supplementary Figs 2 and 3). Compound 15 represents a rare example of a highly sterically hindered ${ }^{18} \mathrm{~F}$-labelled benzene derivative bearing alkyl substituents. We next turned our attention to arenes with substituents at the benzyl position. Three substrates (17-19) underwent ${ }^{18} \mathrm{~F}$-incorporation in modest to good yields (Supplementary Figs 4-6). A protected form of 4- $\left[{ }^{18} \mathrm{~F}\right]$ fluorobenzyl amine (18) - an important building blockwas prepared by the present method in $40 \%$ yield without the requirement of metal-mediated reduction from a nitrile precursor $^{28,29}$.

Radiolabelling of non-activated and/or hindered arenes. A range of other electron-rich arenes, the labelling of which constitutes an unmet need and a historical challenge, proved to be good substrates for the present ${ }^{18} \mathrm{~F}$-labelling strategy. This includes arenes incorporating alkoxy groups 20-23, where 21-23 are concurrently challenged with hindered ortho substituents (Supplementary Figs 7-10). Bromo derivative 22 represents a new building block that could be further functionalized or linked to complex molecular motifs through cross-coupling reactions ${ }^{30}$. Notably, a radiosynthesis of $N$-acetyl $3-\left[{ }^{18} \mathrm{~F}\right]$ fluoroaniline (24) revealed an advantage over previous methods by avoiding the undesired formation of $\left[{ }^{18} \mathrm{~F}\right]$ fluoromethane generated via the reaction of $\left[{ }^{18} \mathrm{~F}\right]$ fluoride with a $N, N, N$-trimethylammonium-3nitrobenzene triflate precursor ${ }^{31}$ (Supplementary Fig. 11). Indoline 25 and pyridine 26 were radiofluorinated in $34 \%$ and $65 \%$ incorporation yield, respectively, demonstrating the broad potential of our method for ${ }^{8} \mathrm{~F}$-labelling of nitrogen-containing heterocycles (Supplementary Figs 12 and 13). 
a Preparation of spiroiodine(III) precursors and radiofluorination

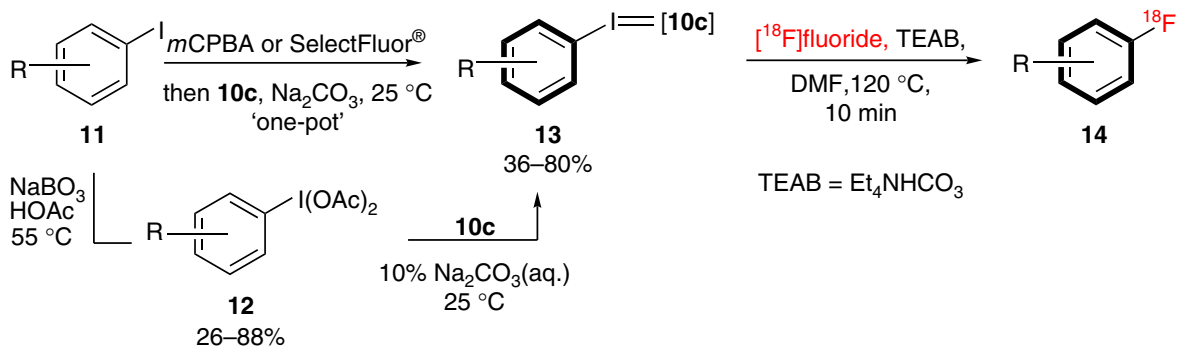

b Fluorination of nonactivated (hetero)arenes with $\left[{ }^{18} \mathrm{~F}\right]$ fluoride ${ }^{a}$

Hindered alkyl substituent<smiles>CC(C)c1cc(C(C)C)c([18OH])c(C(C)C)c1</smiles>

Ether and aniline

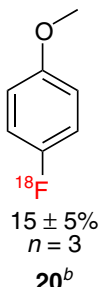

$20^{b}$

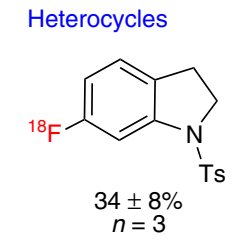

25<smiles>Cc1cc(C)c(F)c(C)c1</smiles>

$45 \pm 13 \%$

$n=3$

16 (ortho)

Substituent at benzyl position
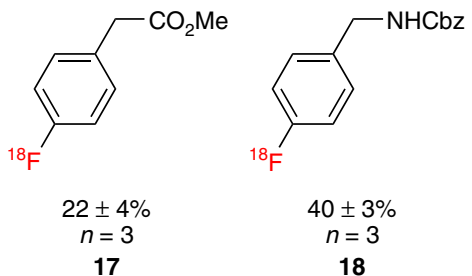

$40 \pm 3 \%$
$n=3$

18<smiles>COCCc1ccc(F)cc1</smiles>

$33 \pm 4 \%$

$n=3$

19

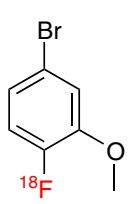

$56 \pm 11 \%$
$n=3$

22 (ortho)<smiles>COC(=O)[C@H](C)Oc1ccccc1F</smiles>

$$
\begin{array}{cc}
7 \pm 1 \% & 17 \pm 3 \% \\
n=3 & n=3 \\
23 \text { (ortho) } & 24^{b}
\end{array}
$$

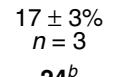

23 (ortho)

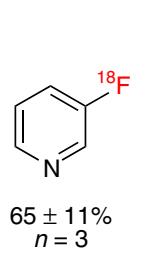

$26^{c}$

Electron-withdrawing group at para position<smiles>O=C(c1ccccc1)c1ccc(F)cc1</smiles>

31

Electron-withdrawing groups at meta position<smiles>Fc1cc(Br)cc(C(F)(F)F)c1</smiles><smiles>Fc1cccc(C(F)(F)F)c1</smiles>

$58 \pm 5 \%$
$n=3$

$71 \pm 19 \%$

$27^{c}$

$28^{c}$<smiles>CC(=O)c1cccc(F)c1</smiles><smiles>Cc1ccc([N+](=O)[O-])cc1F</smiles>

$77 \pm 7 \%$
$n=3$

29
$32 \pm 11 \%$
$n=3$

30 (ortho)

Figure 3 | Scope of spirocyclic hypervalent iodine(III)-mediated radiofluorination. (a) Preparation of spiroiodine(III) precursors and radiofluorination. (b) Fluorination of non-activated (hetero)arenes with [ $\left.{ }^{18} \mathrm{~F}\right]$ fluoride. ${ }^{a}$ Radiolabelling conditions: precursor $(2 \mathrm{mg}), \mathrm{TEAB}(7 \mathrm{mg}), \mathrm{DMF}(400 \mu \mathrm{l}),\left[{ }^{18} \mathrm{~F}\right] \mathrm{fluoride}$ $(1-3 \mathrm{mCi}), 120^{\circ} \mathrm{C} \times 10 \mathrm{~min}$. Incorporation yield was determined by radioTLC. The identity of labelled product was confirmed by radioHPLC. ${ }^{b}$ Reaction temperature $150^{\circ} \mathrm{C}$. ' Incorporation yield was determined by radioHPLC. Non-activated arenes with ortho functionalities are highlighted in yellow. TEAB, tetraethylammonium bicarbonate; $m C P B A$, meta-chloroperoxybenzoic acid.

Arenes displaying electron-withdrawing groups, including trifluoromethyl, halide, nitro and ester substituents at the meta (non-activated) positions (Fig. 3b, 27-30), were also successfully radiofluorinated by the new protocol (Supplementary Figs 14-17). Two arene substrates with the $\mathrm{CF}_{3}$ pharmacophore (27 and 28) were successfully radiolabelled with ${ }^{18} \mathrm{~F}$ at the meta-position in excess of $45 \%$ conversion. Compound 27 demonstrates compatibility with aryl halides and could be further functionalized via coupling reactions $\mathrm{s}^{30}$. Ester 29 was labelled in $77 \%$ conversion and may be directly converted to $3-\left[{ }^{18} \mathrm{~F}\right]$ fluorobenzyl alcohol, which is a key fragment of $\left[{ }^{18} \mathrm{~F}\right]$ lapatinib ${ }^{32}$. In the example of fluorobenzophenone 31, we demonstrated that our method 
Direct radiofluorination of highly-functionalized molecules and PET radiopharmaceuticals

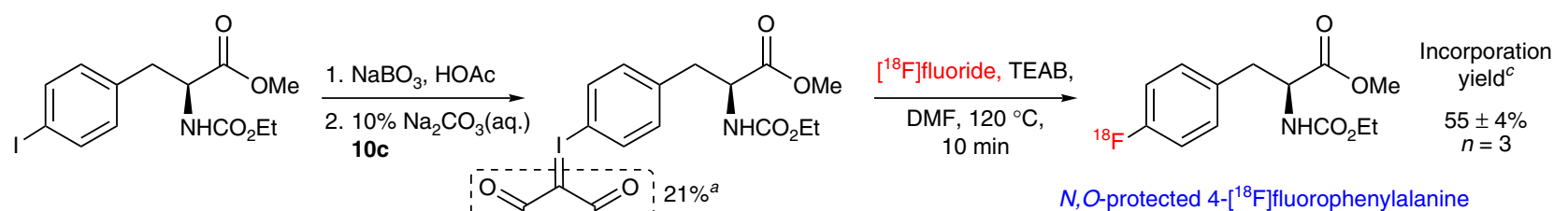

35

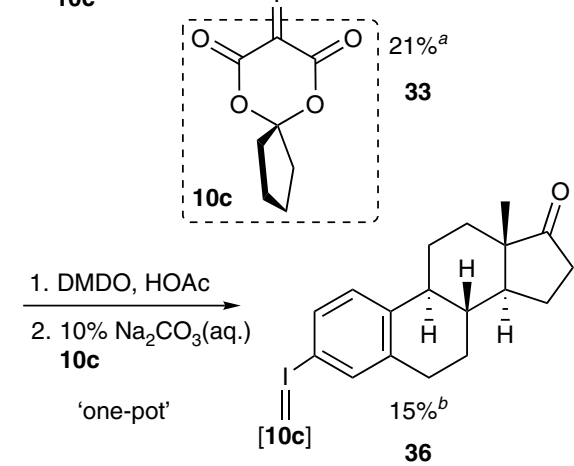

36
34

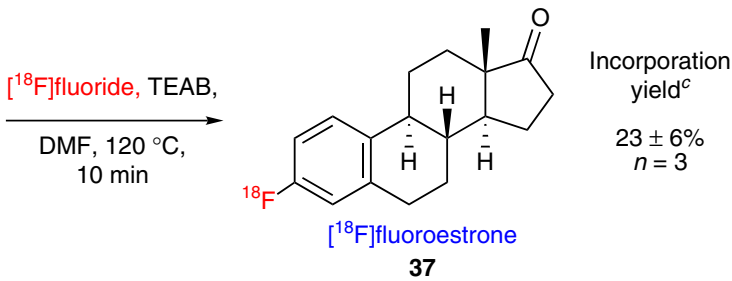

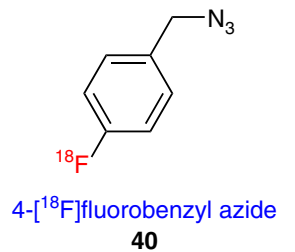

40

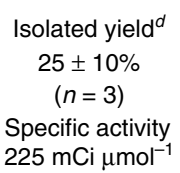

Specific activity
$225{\mathrm{mCi} \mu \mathrm{mol}^{-1}}^{-1}$

38
39

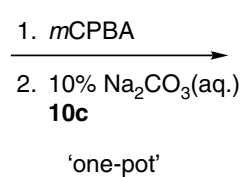

39<smiles>O=c1[nH]cc(F)c(=O)[nH]1</smiles>

$5-\left[{ }^{18} \mathrm{~F}\right] \mathrm{fluorouracil}$

44
Isolated yield ${ }^{d}$

$11 \pm 4 \%$

$(n=3)$

Specific activity ${ }^{e}$ $398{\mathrm{mCi} \mu \mathrm{mol}^{-1}}^{-1}$ $37 \%$
42

$10 \mathrm{~min}$

41

'one-pot'

Figure 4 | Direct radiofluorination of highly functionalized molecules and PET radiopharmaceuticals. (a) Purified by recrystallization. (b) Purified by silica chromatography. (c) Incorporation yield and product identity were determined by radioTLC and radioHPLC, respectively ( $n=3$ ). (d) Reported as uncorrected radiochemical yield and isolated by solid-phase extraction technique $(n=3)$, radiochemical purity $>95 \%$. (e) Specific activity was determined based on intermediate 43. DMDO, dimethyldioxirane; Oxone, potassium peroxysulphate; TFA, trifluoroacetic acid.

worked equally well for an activated arene with an electronwithdrawing group at the para position (Supplementary Fig. 18). Few exceptions for this methodology are expected, which includes precursors with unprotected hydroxy groups, amines and carboxylic acids. The above-mentioned examples demonstrate that this radiofluorination technology is widely applicable in six major classes of arenes and overcomes the challenges in previous methodologies as well as offers unique building blocks that were previously inaccessible.

Chromatographic analysis (radioTLC and radioHPLC) of crude reaction mixtures obtained in the course of this study showed that the sole radioactive products were the ${ }^{18} \mathrm{~F}$ radiolabelled arenes along with unreacted $\left[{ }^{18} \mathrm{~F}\right]$ fluoride. No other radioactive byproducts were detected. The unique selectivity can be, in part, explained by the substantial difference of electron densities between two carbon atoms attached to the I(III) center. A ${ }^{13} \mathrm{C}$ NMR study of our spirocyclic biphenyl based on 10c revealed that the ipso carbon (Fig. 1, 4) resonates significantly downfield (114.3 p.p.m.) relative to the alpha carbon (57.2 p.p.m.) and is less shielded, indicating decreased electron density, and consequently greater propensity towards ${ }^{18} \mathrm{~F}$ during reductive elimination. In contrast, diaryliodonium salts ${ }^{22}$ do not exhibit a dramatic difference in ${ }^{13} \mathrm{C}$ chemical shifts, in accord with the reduced degree of regioselectivity in fluorination.
Translation to PET radiopharmaceuticals. To highlight the practical utility of spirocyclic hypervalent iodine(III)-based radiofluorination, we have demonstrated that established radiotracers that were previously accessible by $\left[{ }^{18} \mathrm{~F}\right] \mathrm{F}_{2}$ and known molecules with sensitive functionalities are well suited for labeling with $\left[{ }^{18} \mathrm{~F}\right]$ fluoride. As shown in Fig. 4, a N,O-protected $\left[{ }^{18} \mathrm{~F}\right]$ fluorophenylalanine, 34, was successfully labelled via the corresponding spiroiodine(III) precursor in 55\% incorporation yield (Supplementary Fig. 19). It is noteworthy that $\left[{ }^{18} \mathrm{~F}\right]$ fluorophenylalanine and its derivatives have only been synthesized via carrier-added $\left[{ }^{18} \mathrm{~F}_{\mathrm{F}} \mathrm{F}_{2}{ }^{33-35}\right.$ or through cumbersome multi-step reactions starting with $\left[{ }^{18} \mathrm{~F}\right]$ fluoride culminating with chiral HPLC separations ${ }^{36}$. $\quad\left[{ }^{18} \mathrm{~F}\right]$ Fluoroestrone (37), previously prepared by transition-metal-mediated methods ${ }^{12,13}$, was also synthesized, in 23\% incorporation yield (Supplementary Fig. 20).

Fluorine-18-labelled azides have found widespread use in 'click' syntheses of ${ }^{18} \mathrm{~F}$-labelled peptides ${ }^{37,38}$. For example, 4- $\left[{ }^{18} \mathrm{~F}\right]$ fluorobenzyl azide (Fig. 4, 40) is a common building block for such reactions that is synthesized by a lengthy four-step route $^{37}$ or via a diaryliodonium salt method using an esoteric flow device ${ }^{39}$. In the present work, we significantly improved and simplified the synthesis of $\mathbf{4 0}$ using a spiroiodine(III) precursor 39, prepared from 4-iodobenzyl azide by a one-pot method, and directly radiolabelled and isolated $\mathbf{4 0}$ in $25 \%$ 
uncorrected radiochemical yield within $40 \mathrm{~min}$, relative to dried $\left[{ }^{18} \mathrm{~F}\right]$ fluoride (Supplementary Figs 21 and 22 and Supplementary Table 2). The methodology presented herein was also used to prepare a PET radiopharmaceutical, 5- $\left[{ }^{18} \mathrm{~F}\right]$ fluorouracil (44), which was difficult to achieve by $\mathrm{S}_{\mathrm{N}} \mathrm{Ar}$ and was previously prepared by an electrophilic $\left[{ }^{18} \mathrm{~F}\right] \mathrm{F}_{2}$ method, that consequently results in low specific activity due to carrier $\mathrm{F}_{2}$ (ref. 40). We converted 5-iodo-2,4-dimethoxypyrimidine to the corresponding spiroiodine(III) precursor 42, which underwent a stepwise radiofluorination and deprotection by aqueous hydrobromic acid, to generate 44 in $11 \%$ isolated uncorrected radiochemical yield from dried $\left[{ }^{18} \mathrm{~F}\right]$ fluoride with a specific activity of $0.4 \mathrm{Ci} \mu \mathrm{mol}^{-1}$ (Supplementary Figs. 23 and 24 \& Supplementary Table 3), representing the radiosynthesis of $5-\left[{ }^{18} \mathrm{~F}\right]$ fluorouracil from nucleophilic $\left[{ }^{18} \mathrm{~F}\right]$ fluoride for the first time. This reaction was carried out using ca. $300 \mathrm{mCi}$ of starting $\left[{ }^{18} \mathrm{~F}\right]$ fluoride for proof of concept. We are presently scaling up and automating this reaction for clinical radiopharmaceutical production.

\section{Discussion}

Spiroiodine(III)-based precursors are stable species that have proven to enable direct and regioselective ${ }^{18} \mathrm{~F}$-labelling of nonactivated and sterically hindered arenes with remarkably broad functional group compatibility. A wide range of non-activated arenes with structurally diverse and/or ortho functional groups, including esters, carbamates, halides, amides, nitro groups, trifluoromethyl groups, ketones and heterocycles, were efficiently radiolabelled by the developed method. Several ${ }^{18}$ F-PET tracers and building blocks were successfully synthesized from $\left[{ }^{18} \mathrm{~F}\right]$ fluoride ion for the first time and/or the corresponding radiosyntheses were significantly simplified and improved via one-step reactions. Radiotracers prepared by this methodology were shown to be easily isolated in high radiochemical yields and specific acitivies, suitable for clinical translation.

\begin{abstract}
Methods
General methods for radioisotope production and preparation. A GE PETtrace $16.5 \mathrm{MeV}$ cyclotron was used for $\left[{ }^{18} \mathrm{~F}\right]$ fluoride production by the ${ }^{18} \mathrm{O}(\mathrm{p}, \mathrm{n}){ }^{18} \mathrm{~F}$ nuclear reaction to irradiate ${ }^{18} \mathrm{O}$-enriched water. $\left[{ }^{18} \mathrm{~F}\right]$ fluoride was delivered to a lead-shielded hot cell in ${ }^{18} \mathrm{O}$-enriched water by nitrogen gas pressure. $\left[{ }^{18} \mathrm{~F}\right]$ fluoride was prepared for radiofluorination of aromatics by one of two methods: (A) A solution of base (for example, TEAB, $7 \mathrm{mg}$ ) in acetonitrile and water $(1 \mathrm{ml}, \mathrm{v} / \mathrm{v} 7: 3)$ was added to an aliquot of target water $(\leq 1 \mathrm{ml})$ containing the appropriate amount of $\left[{ }^{18} \mathrm{~F}\right]$ fluoride in a V-shaped vial sealed with a teflon-lined septum. The vial was heated to $110^{\circ} \mathrm{C}$ while nitrogen gas was passed through a $\mathrm{P}_{2} \mathrm{O}_{5}$-Drierite column followed by the vented vial. When no liquid was visible in the vial, it was removed from heat, anhydrous acetonitrile $(1 \mathrm{ml})$ was added and the heating was resumed until dryness. This step was repeated an additional three times. The vial was then cooled at room temperature under nitrogen pressure. The contents were resolubilized in the desired solvent (for example, DMF). (B) An aliquot of target water containing the appropriate amount of $\left[{ }^{18} \mathrm{~F}\right]$ fluoride was slowly passed through an anion exchange cartridge (MP1, ORTG, TN, USA), preactivated by flushing with $\mathrm{NaHCO}_{3(\mathrm{aq})}(8.4 \%, 1 \mathrm{ml})$ and water $(2-3 \mathrm{ml}$, until neutral by a $\mathrm{pH}$ indicator). $\left[{ }^{18} \mathrm{~F}\right]$ fluoride was eluted using a solution of base (for example, TEAB, $7 \mathrm{mg})$ in acetonitrile and water $(1 \mathrm{ml}, \mathrm{v} / \mathrm{v} 7: 3)$ into a V-shaped vial sealed with a teflon-lined septum. Drying and resolubilization were then performed as described above. For preparations involving crypt-222, drying was conducted at $95^{\circ} \mathrm{C}$.
\end{abstract}

General methods for analysis of radiofluorination reactions. Radioactivity was quantified using a Capintec Radioisotope Calibrator (CRC-712M) ion chamber. Radiochemical incorporation yields were determined by radioTLC. EMD TLC Silica gel 60 plates $\left(10 \times 2 \mathrm{~cm}^{2}\right)$ were spotted with an aliquot $(1-5 \mu \mathrm{l})$ of crude reaction mixture $\sim 1.5 \mathrm{~cm}$ from the bottom of the plate (baseline). Unless otherwise noted, TLC plates were developed in a chamber containing ethyl acetate until within $2 \mathrm{~cm}$ of the top of the plate (front). Analysis was performed using a Bioscan AR-2000 radio-TLC imaging scanner and WinScan software. Radiochemical identity and purity were determined by radioHPLC. A Phenomenex Luna C18, $250 \times 4.6 \mathrm{~mm}, 5 \mu \mathrm{m}$ HPLC column was used with a Waters 1515 Isocratic HPLC Pump equipped with a Waters 2487 Dual $\lambda$ Absorbance Detector, a Bioscan FlowCount equipped with a NaI crystal and Breeze software. Mobile phases and flowrates included $70 \% \mathrm{CH}_{3} \mathrm{CN}, 30 \% 0.1 \mathrm{M} \mathrm{NH}_{4} \cdot \mathrm{HCO}_{2(\mathrm{aq})}, 1 \mathrm{ml} \mathrm{min}{ }^{-1} ; 50 \%$ $\mathrm{CH}_{3} \mathrm{CN}, 50 \% 0.1 \mathrm{M} \mathrm{NH}_{4} \cdot \mathrm{HCO}_{2(\mathrm{aq})}, 1 \mathrm{ml} \mathrm{min}^{-1}$, and $5 \% \mathrm{EtOH}, 95 \% 0.1 \%$ $\mathrm{AcOH}_{(\mathrm{aq})}, 1 \mathrm{ml} \mathrm{min}^{-1}$

In order to account for immobilized radioactivity (which would not be accounted for by radioTLC), reaction vessels were decanted after quenching, and residual and solution radioactivity were separately quantified. In all cases, $\geq 95 \%$ of radioactivity remained in solution.

General procedure for radiofluorination of arenes. Azeotropically dried $\left[{ }^{18} \mathrm{~F}^{2} \mathrm{Et}_{4} \mathrm{NF}\right.$ (typically $\left.1-3 \mathrm{mCi}, 37-110 \mathrm{MBq}\right)$, resolubilized in DMF $(400 \mu \mathrm{l})$, was added to a $\mathrm{V}$-vial containing spiroiodine(III) precursor $(13,2 \mathrm{mg})$. The reaction was heated at $120^{\circ} \mathrm{C}$ for $10 \mathrm{~min}$, and quenched with HPLC buffer (for example, $60: 40 \mathrm{CH}_{3} \mathrm{CN}: \mathrm{H}_{2} \mathrm{O}+0.1 \mathrm{~N}$ ammonium formate, $1 \mathrm{ml}$ ). Fluorine incorporation and product identities were determined by radioTLC and radioHPLC $(n \geq 3)$. For radioTLC and radioHPLC data, see Supplementary Figs 1-22.

Conditions were optimized for radiofluorination of $10 \mathrm{c}$ to produce $\left[{ }^{18} \mathbf{F}\right] 7$. Radiofluorination of all other substrates was performed under identical conditions and they remained unoptimized. For certain products that were detected in low yield (that is, 20, 24), a reaction temperature of $150^{\circ} \mathrm{C}$ proved superior to the general procedure temperature of $120^{\circ} \mathrm{C}$.

Specific activity of isolated radioactive products. Specific activity was determined by measurement of the UV absorbance of a known amount of radioactivity under identical analytical HPLC conditions used to generate a calibration curve for the corresponding nonradioactive standard. See Supplementary Figs 22 and 24, and Supplementary Tables 2 and 3 for details.

General procedure for synthesis of iodonium ylides. To a solution of the auxiliary acid $(\mathbf{8}-\mathbf{1 0}, 0.25 \mathrm{mmol})$ in $10 \% \mathrm{Na}_{2} \mathrm{CO}_{3(\mathrm{aq})}(\mathrm{w} / \mathrm{v}, 0.75 \mathrm{ml}, 0.33 \mathrm{M}$ solution) was added ethanol $(1 \mathrm{ml})$ followed quickly by diacetoxyiodoarene $(\mathbf{1 1}, 0.25 \mathrm{mmol})$. The reaction mixture was vigorously stirred at room temperature for $0.5-4 \mathrm{~h}$, until full conversion of starting materials was determined by TLC. The reaction mixture was then diluted with water $(\sim 8 \mathrm{ml})$, and extracted with DCM $(3 \times 10 \mathrm{ml})$. The combined organic extracts were dried with anhydrous $\mathrm{Na}_{2} \mathrm{SO}_{4}$, filtered and concentrated. To the residue was added ethyl acetate and hexanes to induce precipitation (at room temperature or $-25^{\circ} \mathrm{C}$ ). Solids were collected by filtration and purified by flash chromatography if necessary. For ${ }^{1} \mathrm{H},{ }^{13} \mathrm{C}$ and ${ }^{19} \mathrm{~F}$ spectra of new compounds, see Supplementary Figs 25-118.

\section{References}

1. Fowler, J. S. \& Wolf, A. P. Working against time: rapid radiotracer synthesis and imaging the human brain. Acc. Chem. Res. 30, 181-188 (1997).

2. Phelps, M. E. Positron emission tomography provides molecular imaging of biological processes. Proc. Natl Acad. Sci. USA 97, 9226-9223 (2000).

3. Ametamey, S. M., Honer, M. \& Schubiger, P. A. Molecular imaging with PET. Chem. Rev. 108, 1501-1516 (2008).

4. Cai, L., Lu, S. \& Pike, V. W. Chemistry with [18F]fluoride ion. Eur. J. Org. Chem. 2008, 2853-2873 (2008).

5. Miller, P. W., Long, N. J., Vilar, R. \& Gee, A. D. Synthesis of 11C, 18F, 15O, and $13 \mathrm{~N}$ radiolabels for positron emission tomography. Angew. Chem. Int. Ed. 47, 8998-9033 (2008).

6. Holland, J. P. et al. Alternative approaches for PET radiotracer development in Alzheimer's disease: imaging beyond plaque.. J. Labelled Compd. Radiopharm. 57, 323-331 (2014).

7. Balz, G. \& Schiemann, G. Über aromatische Fluorverbindungen, I.: Ein neues Verfahren zu ihrer Darstellung. Ber. dtsch. Chem. Ges. A/B 60, 1186-1190 (1927).

8. Wallach, O. Ueber das Verhalten einiger Diazo- und Diazoamidoverbindungen. Justus Liebigs Ann. Chem. 235, 233-255 (1886).

9. $\mathrm{Mu}, \mathrm{L}$. et al. $18 \mathrm{~F}$-radiolabeling of aromatic compounds using triarylsulfonium salts. Eur. J. Org. Chem. 2012, 889-892 (2012).

10. Chun, J.-H., Morse, C. L., Chin, F. T. \& Pike, V. W. No-carrier-added $[18 \mathrm{~F}]$ fluoroarenes from the radiofluorination of diaryl sulfoxides. Chem. Commun. 49, 2151-2153 (2013).

11. Wagner, F. M., Ermert, J. \& Coenen, H. H. Three-step, “one-pot” radiosynthesis of 6-fluoro-3,4-dihydroxy-1-phenylalanine by isotopic exchange. J. Nucl. Med. 50, 1724-1729 (2009).

12. Lee, E., Hooker, J. M. \& Ritter, T. Nickel-mediated oxidative fluorination for PET with aqueous [18F] fluoride. J. Am. Chem. Soc. 134, 17456-17458 (2012).

13. Lee, E. et al. A fluoride-derived electrophilic late-stage fluorination reagent for PET imaging. Science 334, 639-642 (2011).

14. Gao, Z. et al. Metal-free oxidative fluorination of phenols with [18F]fluoride. Angew. Chem. Int. Ed. 51, 6733-6737 (2012).

15. Pike, V. W. \& Aigbirhio, F. I. Reactions of cyclotron-produced [18F]fluoride with diaryliodonium salts-a novel single-step route to no-carrier-added [18]fluoroarenes. J. Chem. Soc. Chem. Commun. 2215-2216 (1995). 
16. Shah, A., Pike, V. W. \& Widdowson, D. A. The synthesis of [18F]fluoroarenes from the reaction of cyclotron-produced [18F]fluoride ion with diaryliodonium salts. J. Chem. Soc. Perkin Trans. 1 2043-2046 (1998).

17. Ross, T. L., Ermert, J., Hocke, C. \& Coenen, H. H. Nucleophilic 18Ffluorination of heteroaromatic iodonium salts with no-carrier-added [18F]fluoride. J. Am. Chem. Soc. 129, 8018-8025 (2007).

18. Yusubov, M. S., Maskaev, A. V. \& Zhdankin, V. V. Iodonium salts in organic synthesis. ARKIVOC 2011, 370-409 (2011).

19. Yusubov, M. S., Svitich, D. Y., Larkina, M. S. \& Zhdankin, V. V. Applications of iodonium salts and iodonium ylides as precursors for nucleophilic fluorination in positron emission tomography. ARKIVOC 2013, 364-395 (2013).

20. Carroll, M. A., Jones, C. \& Tang, S.-L. Fluoridation of 2-thienyliodonium salts. J. Labelled Compd. Radiopharm. 50, 450-451 (2007).

21. Satyamurthy, N. \& Barrio, J. R. No-carrier-added nucleophilic [F-18] fluorination of aromatic compounds. WO2010/117435 A2 (2010).

22. Moon, B. S. et al. Facile aromatic radiofluorination of $[18 \mathrm{~F}]$ flumazenil from diaryliodonium salts with evaluation of their stability and selectivity. $\mathrm{Org}$. Biomol. Chem. 9, 8346-8355 (2011).

23. Wang, B., Cerny, R. L., Uppaluri, S., Kempinger, J. J. \& Dimagno, S. G. Fluoride-promoted ligand exchange in diaryliodonium salts. J. Fluorine Chem. 131, 1113-1121 (2010).

24. Martin-Santamaria, S. et al. Fluoridation of heteroaromatic iodonium saltsexperimental evidence supporting theoretical prediction of the selectivity of the process. Chem. Commun. 649-650 (2000)

25. Graskemper, J. W., Wang, B., Qin, L., Neumann, K. D. \& DiMagno, S. G. Unprecedented directing group ability of cyclophanes in arene fluorinations with diaryliodonium salts. Org. Lett. 13, 3158-3161 (2011).

26. Wang, B., Graskemper, J. W., Qin, L. \& DiMagno, S. G. Regiospecific reductive elimination from diaryliodonium salts. Angew. Chem. Int. Ed. 49, 4079-4083 (2010).

27. Reed, C. D., Launay, G. G. \& Carroll, M. A. Evaluation of tetraethylammonium bicarbonate as a phase-transfer agent in the formation of [18F]fluoroarenes. $J$. Fluorine Chem. 143, 231-237 (2012).

28. Turkman, N. et al. Synthesis and preliminary evaluation of [18F]-labeled 2oxoquinoline derivatives for PET imaging of cannabinoid CB2 receptor. Nucl. Med. Biol. 39, 593-600 (2012).

29. Koslowsky, I., Mercer, J. \& Wuest, F. Synthesis and application of 4 - $[18 \mathrm{~F}]$ fluorobenzylamine: a versatile building block for the preparation of PET radiotracers. Org. Biomol. Chem. 8, 4730-4735 (2010).

30. Pretze, M., Große-Gehling, P. \& Mamat, C. Cross-coupling reactions as valuable tool for the preparation of PET radiotracers. Molecules 16, 1129-1165 (2011).

31. Vasdev, N. et al. Metabolic stability of 6,7-dialkoxy-4-(2-, 3- and 4 -[18F]fluoroanilino)quinazolines, potential EGFR imaging probes. Bioorg. Med. Chem. 19, 2959-2965 (2011).

32. Basuli, F. et al. A first synthesis of $18 \mathrm{~F}$-radiolabeled lapatinib: a potential tracer for positron emission tomographic imaging of ErbB1/ErbB2 tyrosine kinase activity. J. Labelled Compd. Radiopharm. 54, 633-636 (2011).

33. Coenen, H. H., Franken, K., Kling, P. \& Stöcklin, G. Direct electrophilic radiofluorination of phenylalanine, tyrosine and dopa. Int. J. Radiat. Appl. Instrum. 39, 1243-1250 (1988).
34. Namavari, M., Satyamurthy, N., Phelps, M. E. \& Barrio, J. R. Synthesis of $6-[18 \mathrm{~F}]$ and $4-[18 \mathrm{~F}]$ fluoro-l-m-tyrosines via regioselective radiofluorodestannylation. Appl. Radiat. Isot. 44, 527-536 (1993).

35. VanBrocklin, H. F. et al. A new precursor for the preparation of 6-[18F]Fluorol-m-tyrosine ([18F]FMT): efficient synthesis and comparison of radiolabeling. Appl. Radiat. Isot. 61, 1289-1294 (2004).

36. Lemaire, C., Guillaume, M., Christiaens, L., Palmer, A. J. \& Cantineau, R. A new route for the synthesis of $[18 \mathrm{~F}]$ fluoroaromatic substituted amino acids: no carrier added L-p-[18F]fluorophenylalanine. Appl. Radiat. Isot. 38, 1033-1038 (1987).

37. Thonon, D., Kech, C., Paris, J., Lemaire, C. \& Luxen, A. New strategy for the preparation of clickable peptides and labeling with 1-(azidomethyl)-4-[18F]fluorobenzene for PET. Bioconjugate Chem. 20, 817-823 (2009).

38. Campbell-Verduyn, L. S. et al. Strain-promoted copper-free "click" chemistry for $18 \mathrm{~F}$ radiolabeling of Bombesin. Angew. Chem. Int. Ed. 50, 11117-11120 (2011)

39. Chun, J.-H. \& Pike, V. W. Single-step radiosynthesis of " 18 F-labeled click synthons" from azide-functionalized diaryliodonium salts. Eur. J. Org. Chem. 2012, 4541-4547 (2012).

40. Fowler, J. S., Finn, R. D., Lambrecht, R. M. \& Wolf, A. P. The synthesis of 18F-5-fluorouracil. VII. J. Nucl. Med. 14, 63-64 (1973).

\section{Acknowledgements}

B.H.R. is a Natural Sciences and Engineering Research Council of Canada (NSERC) Postdoctoral Fellow. We thank Dr Thomas Lee Collier, Dr Jason P. Holland, Professor Thomas J. Brady and Professor Marco A. Ciufolini for helpful discussions. We also thank Jon Patteson, Rebecca Lewis and Alina Kassenbrock for technical support, and Dr Ronald Moore and David F. Lee, Jr., for isotope production.

\section{Author contributions}

B.H.R. and N.A.S. contributed equally to the work and performed the synthesis and radiofluorination experiments. All authors contributed to the design and development of the method and application. N.V. and S.H.L. prepared the manuscript, guided and supervised the project. All the authors discussed the experimental results and commented on the manuscript.

\section{Additional information}

Supplementary Information accompanies this paper at http://www.nature.com/ naturecommunications

Competing financial interests: The authors declare no competing financial interests.

Reprints and permission information is available online at http://npg.nature.com/ reprintsandpermissions/

How to cite this article: Rotstein, B. H. et al. Spirocyclic hypervalent iodine(III)mediated radiofluorination of non-activated and hindered aromatics. Nat. Commun. 5:4365 doi: 10.1038/ncomms5365 (2014). 